\title{
Retrofitting residential buildings in the University of Sharjah
}

\author{
Emad Mushtaha ${ }^{1,}$, , Sondos Ayman Jara ${ }^{1}$, Nour Ali Tahmaz ${ }^{1}$ \\ 1,2 Architectural Engineering Department, University of Sharjah, UAE
}

\begin{abstract}
The aim of the research is to investigate best retrofitting strategies that minimizing energy consumption within the context of thermal comfort. The research has targeted two residential compounds in the University of Sharjah: Al Khwarizmi and Al Baironi. Climate Consultant and ECOTECT were used in the simulation process in order to select best passive strategies and tools for the retrofitting. Several parameters such as building orientation, shading devices, and glazing types, were tested during the simulation process. As a result, the study determined the most suitable tools for the existing compounds. The study showed that the use of double glazing with shading devices reduced cooling loads in Al Baironi with 5.42 MWh and 8.13 MWh in $\mathrm{Al}$ Khwarizmi. Also, addressed that U-shaped residential layout is more efficient than liner-shaped layout.
\end{abstract}

\section{Introduction}

\subsection{Brief description}

$\mathrm{Al}$ Khwarizmi and Al Al Baironi are faculty compounds located in the University City of Sharjah (Fig.1.1-2.2). The residence has several types of two, three, and four-bedroom villas where they are designed similar in both compounds, but oriented and formed differently regarding the surrounding opened spaces. The villas in Al Baironi compound are formed linearly unlike Al Khwarizmi compound formed in U blocks. Four- bedroom villas have an approximate area of 216.330 sq.m designed for families with a minimum number of 5 members. The villa consists of a living room connected directly with a dining room with its service area, i.e. (toilet, kitchen, maid room with its own toilet and a small store on the ground floor). The first floor consists of 3 bedrooms with one shared bathroom and one master bedroom besides an office (Fig. 3.1-3.3). As the number of students is in an increase in the University of Sharjah, therefore more faculty members are expected to join the university. Providing more villas and residences to new faculties is the trend in the university. As faculties work for almost 9 hours a day during weekdays, so when they return home they need to rest and feel comfortable. On the other hand, the university pays around AED 70 Million yearly to Sharjah Electricity and Water Authority (SEWA) for its water and electricity consumption. Therefore, providing healthy and efficient buildings can contribute in solving such issue. However, existing buildings, including residences are a

\footnotetext{
${ }^{*}$ Corresponding author: emushtaha@sharjah.ac.ae
} 
part of the solution. Retrofitting existing buildings in the context of thermal comfort is urgently needed. Villas need to be carefully analyzed and improved using passive design tools such as shading devices, glazing, and natural ventilation. Building orientation and form should also be considered because it plays a major role in affecting the energy gained and lost by buildings and this has a large influence on the thermal performance of buildings.

Comfort is the result of the interaction of physical exchanges, physiological, psychological, social and cultural rights; it depends on the architecture, the clothing, the eating habits and the climate as defined in the article (K. Fabbri, 2015). Thermal comfort studies started in the twentieth century when Gagge AP started to solve particular problems due to stressful situations in the workplace. In the twentieth century the architectural theories (Movement modernity, , Functionalism, Bauhaus, Le Corbusier with Le Modulor, De Stijl, CIAM International style, etc.) and technical manuals have put man at the center, as an individual with a physical dimension, founding an interest in the design and construction of residential buildings.

\subsection{Photos, top views and floors plans}

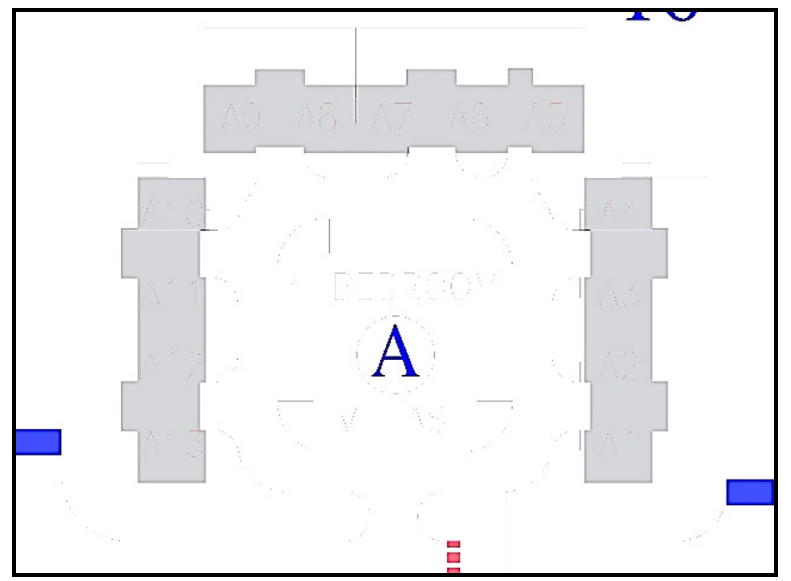

Fig. 1.2.1. Al Khawarizmi Compound - Top View.

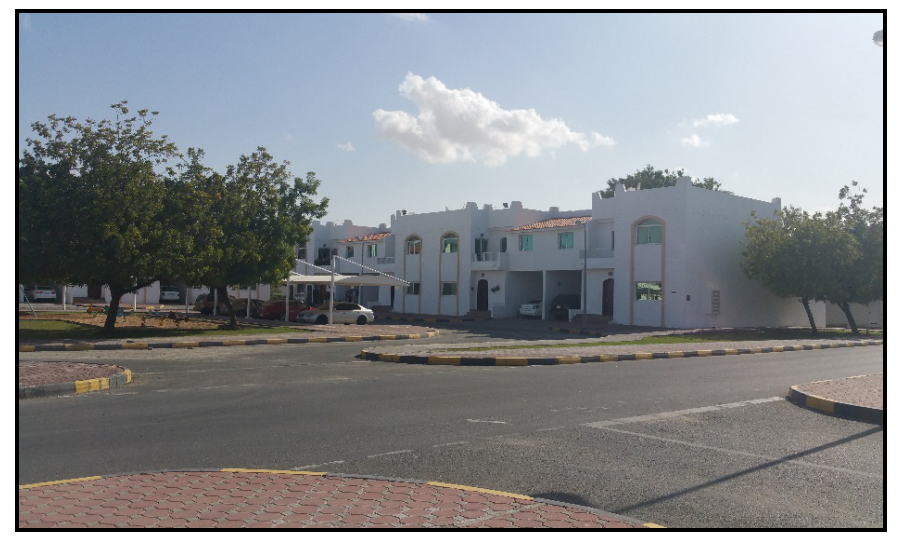

Fig. 1.2.2. Al Khwarizmi Compound - Street View. 


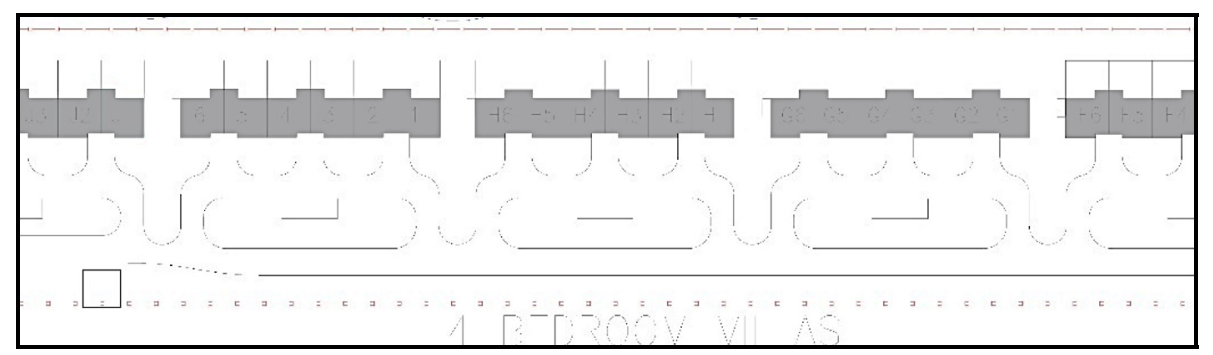

Fig. 1.2.3. Al Bayrouni Compound - Top View.

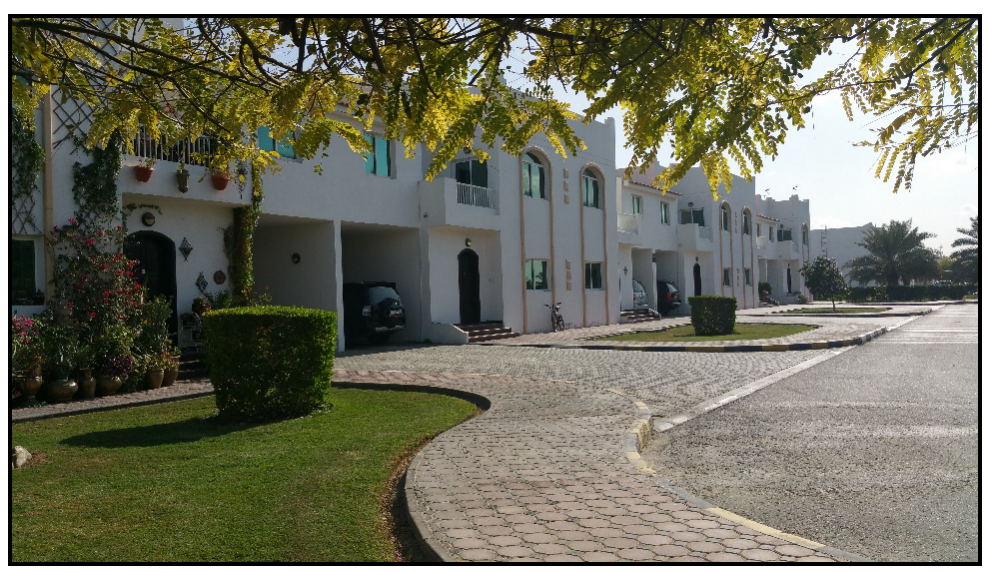

Fig. 1.2.4. Al Baironi Compound - Street View.

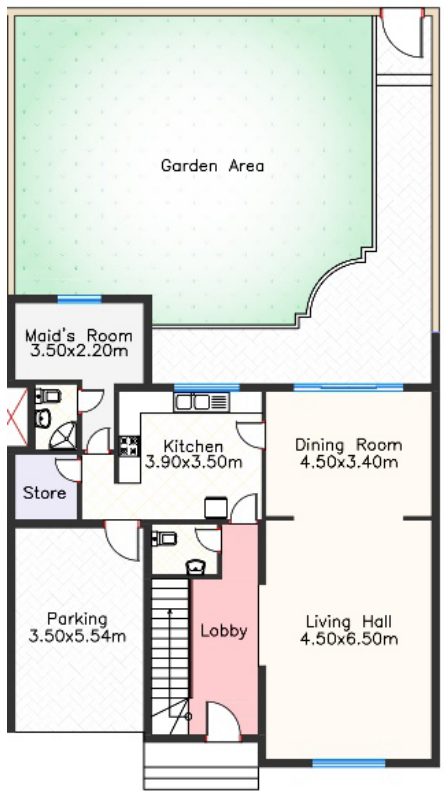

Fig. 1.2.5. Typical Ground Floor Plan. 


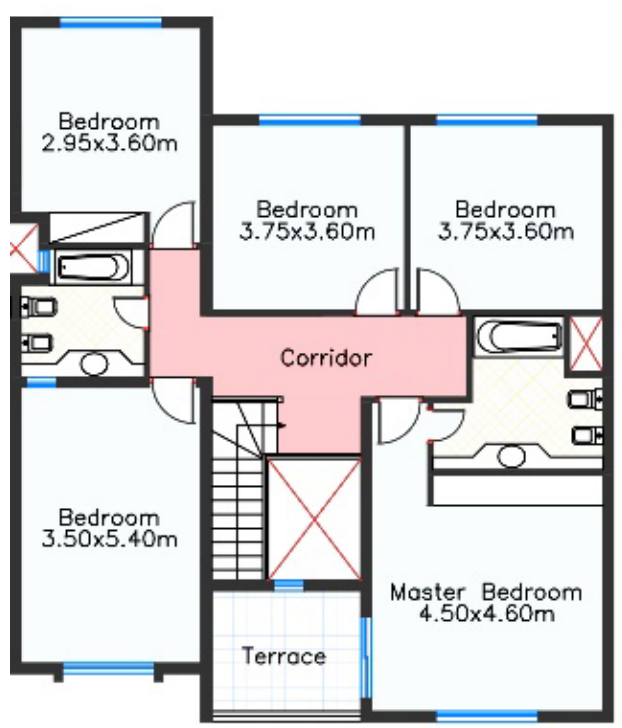

Fig. 1.2.6. Typical First Floor Plan.

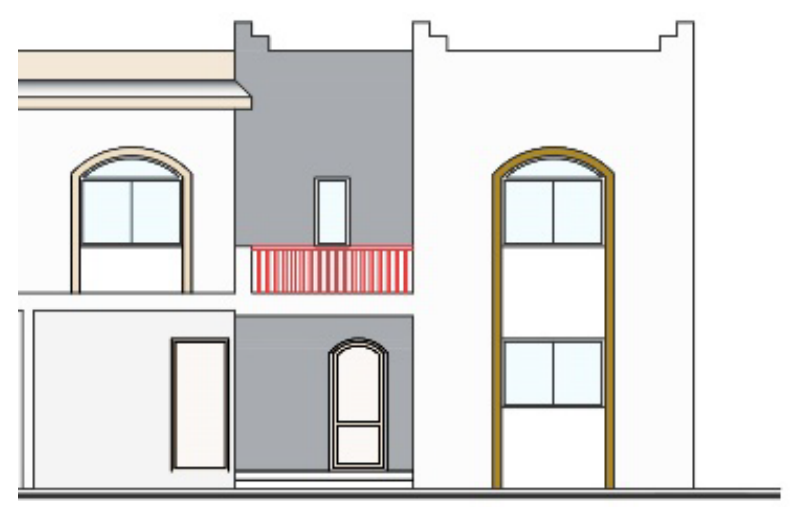

Fig. 1.2.7. Typical Front Elevation.

\subsection{Photos and top views}

UAE is one of the GCC countries in the Middle East that has high-recorded temperature and high humidity ratio, which makes the environment not comfortable. Thus, most of the activities have been done indoor as residents prefer to escape from the annoying weather. Studying the thermal comfort during the year, the authors have gone through certain analysis and researches for each month taking into consideration which months are cold and warm. December, January, February and March are cold months but not discomfort. From April to May there will be a slight stress in temperature if people prolonged their exposure to sun. During the summer starting from late May to September temperature is extremely high with an average of temperature above $41{ }^{\circ} \mathrm{C}$ ( Fig. 1.3.1). 


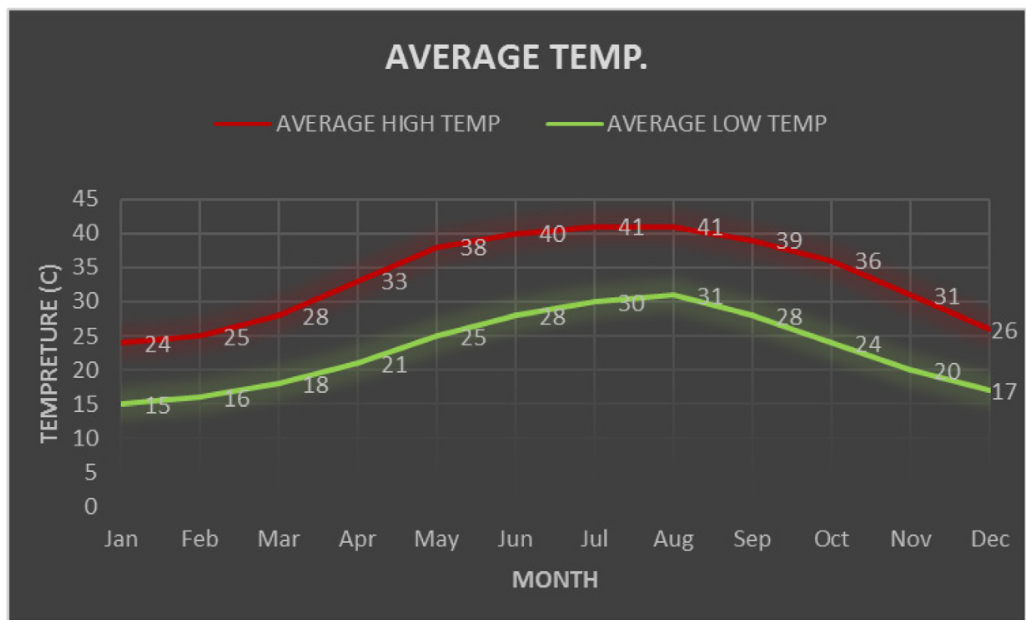

Fig. 1.3.1. Sharjah Average Temperature for Sharjah, UAE.

Figure 1.3.2 shows that 1633 hours are warm and need shading in order to achieve thermal comfort, while 901 hours are located within and slightly below thermal comfort. From the chart, it is obvious that warm hours are almost double than comfort hours in the year.
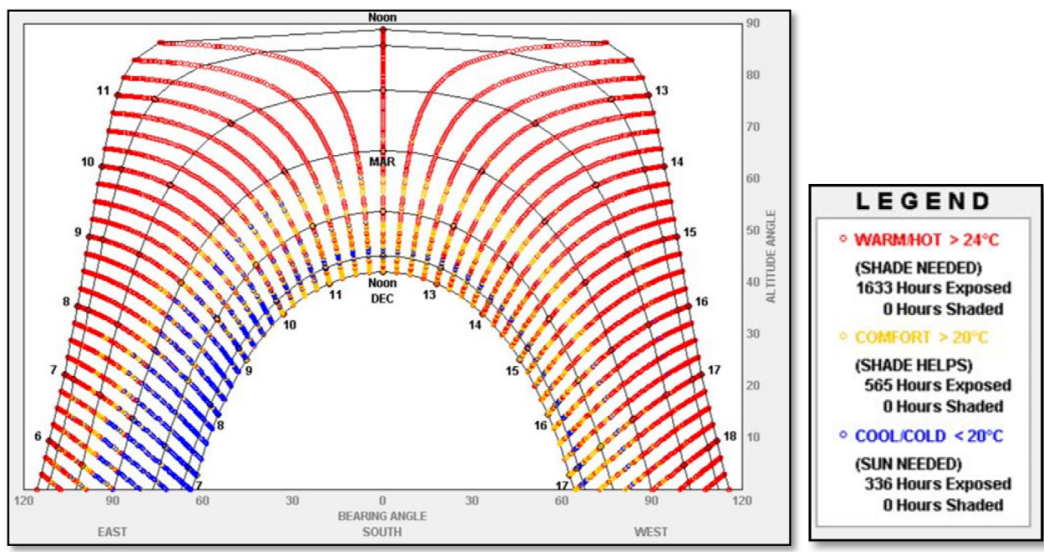

Fig. 1.3.2. Thermal Comfort on South elevation and Sun Shading Chart. 


\section{Research objectives}

This paper aims to evaluate the planning and designing of housing environment in the compound by studying the impact of residences' forms on its thermal performance. Also, it aims at deriving strategies and suggestions that help in reducing energy consumption for four- bedrooms villas.

\section{Methodology}

The analysis of the two compounds in context of the thermal comfort went through the following:

1. Understanding UAE climate and the strategies required to help achieve thermal comfort by integrating Climate Consultant software into the study.

2. Analyzing buildings orientation, heat gain breakdown, and heating and cooling loads by using Ecotect software.

\section{Research framework}

The research addresses the baseline case first followed by several cases to improve the original case. Deciding the required cooling strategies for an area requires an integration of Climate Consultant into the study. From the study, several strategies were listed to improve thermal environment shown in Fig.4.1. Out of the strategies, building orientation, shading devices, and glazing were investigated in both compounds as shown in Table 1.
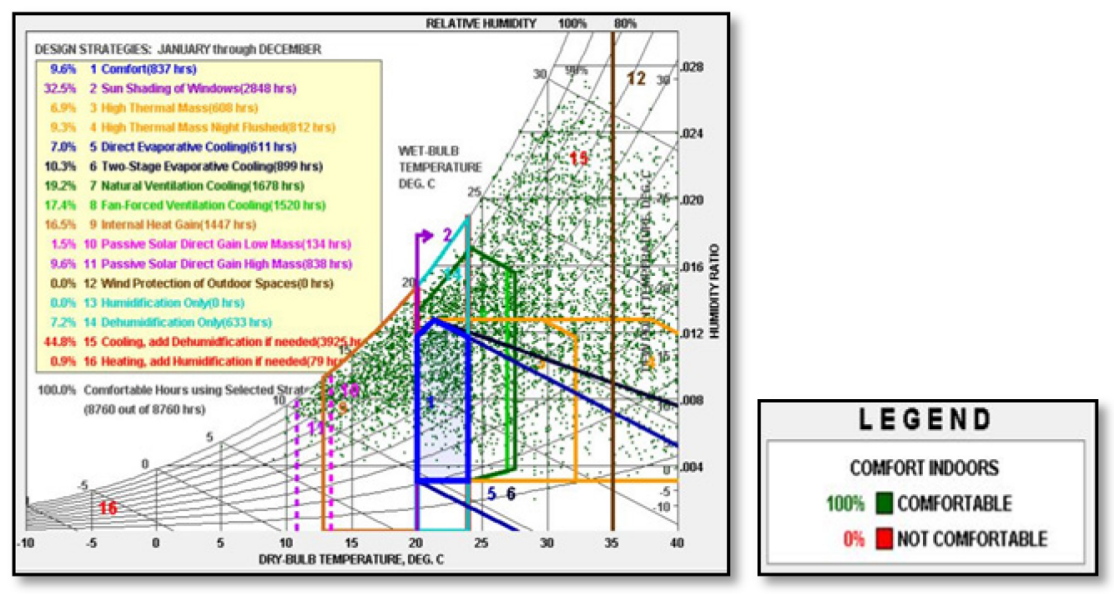

Fig. 4.1. Design Strategies by Climate Consultant.

Table 1. Simulation Cases.

\begin{tabular}{|l|l|}
\hline Case 1 :Al Khawarizmi Compound \\
\hline Case 1 & Baseline Case with Single Glazing \\
\hline Case 1A & Double Glazing \\
\hline Case 1B & Shading Device \\
\hline Case 1C & Double Glazed + Shading Device \\
\hline
\end{tabular}




\begin{tabular}{|l|l|}
\hline Case 2 : Al Al Baironi Compound \\
\hline Case 2 & Baseline Case with Single Glazing \\
\hline Case 2 A & Double Glazing \\
\hline Case 2 B & Shading Device \\
\hline Case 2 C & Double Glazed + Shading Device \\
\hline
\end{tabular}

\subsection{Building orientation}

\section{- Al Khawarizmi Compound}

The main façade of the compound that shows the windows of the living rooms and two bedrooms is facing northeast. Therefore, this façade does not need shading devices unlike the backside façade of two bedrooms, office and kitchen that needs shade as it is facing southwest where heat gain is maximum due to sun low angle in the sky and to accumulated heat during the day. To improve the orientation of this building, an analysis using ECOTECT suggested the best orientation to be $180^{\circ}$ degrees from north for Al Khwarizmi compound.

\section{- Al Al Baironi Compound}

The main façade of the compound that show windows of the living room and two bedrooms is facing northwest. Therefore, this façade does not need shading devices unlike the backside façade of two bedrooms, the office and the kitchen needs to be shaded since it is facing southeast. To improve the orientation of this case, the best suggested orientation for Al Baironi compound was also set to $180.0^{\circ}$ degrees from North.

\subsection{Shading devices}

\section{- Al Khwarizmi and Al Baironi Compounds}

The front façade does not have any shading devices, while the backside of the villa has horizontal shading devices for the kitchen and the living room at ground floor unlike the first floor has no shading devices. To improve the case, shading devices were added to the simulation for the backside façade in the first floor since it is facing southwest. Same simulation process was performed for the case of Al Baironi.

\subsection{Glazing Type}

\section{- Al Khwarizmi and Al Baironi Compounds}

The existing glazing in both villas is Single Glazed Aluminum Frame, which has high ratio of heat gain and loss. To improve this case, Double Glazed Aluminum Frame has been added to the simulation.

\section{Analysis and result}

\subsection{Building orientation}

The orientation of the building plays a major role in affecting the thermal comfort and the consumption of energy in buildings. The weather tool in the Ecotect software analyzes the solar radiation and calculates the best building orientation according to the solar heat absorbed in annual super-heated and under- heated periods Fig.5.1. The green line represents the orientation of the building that gets the highest solar radiation during winter; the thin red line represents the orientation of the building that gets the highest solar radiation in summer, while the yellow line represents the best orientation after 
comprehensive consideration of local meteorological condition. The best orientation for the $\mathrm{Al}$ Khwarizmi and Al Baironi compound villas was $180.0^{\circ}$ degrees from north (Fig.5.1).

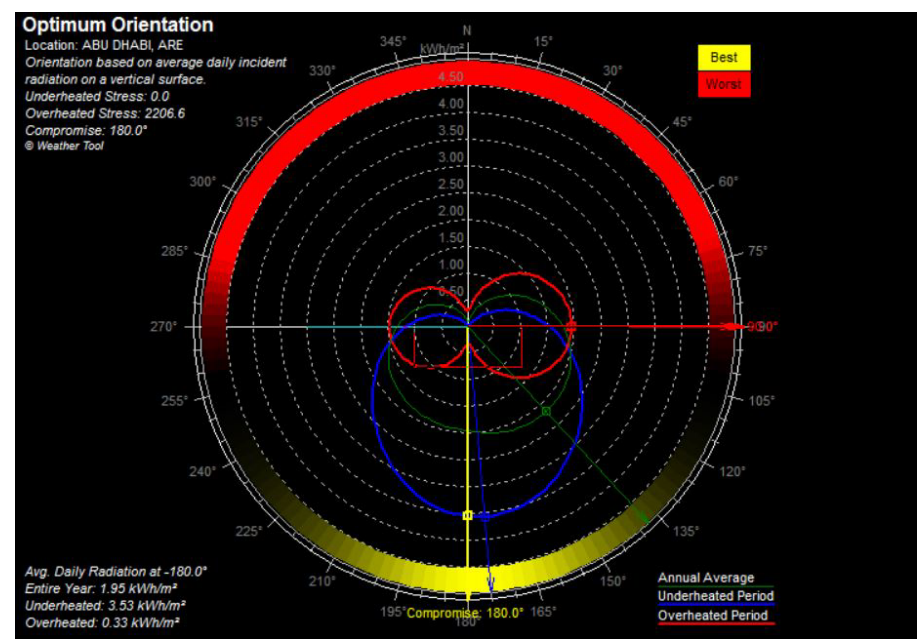

Fig. 5.1. Analysis of the Best Building Orientation of Al Khwarizmi and Al Baironi Compound.

\subsection{HVAC}

HVAC is the amount of energy that is required to maintain the zones at a comfortable indoor temperature. Heat gains breakdown consist of different categories starting with building conduction, which is heat gains/losses that occur through the fabric of the building itself. The Sol-Air gains are due to indirect solar exposure and known as Sol-Air temperature. These heat gains are caused by the molecular excitation within the building materials when exposed to solar radiation. Direct solar heat gains occur through transparent surfaces such as skylights and windows. On the other hand, natural ventilation represents gain and losses that happen due to infiltration. Other factors affecting cooling loads beside earlier parameters like internal gains due to artificial lighting, occupancy by people and equipment. For the Inter-zonal gains and losses that occur between adjacent zones, heat flows from one zone to another.

\subsection{Simulation Analysis}

This section highlights the analysis of earlier simulation cases for both compounds as follows:

\section{- Case1: Baseline Case with Single Glazing Panes}

Using ECOTECT, several simulations were run for the baseline case from 1 June to 30 Sep., i.e. summer months. Different percentages of heat gains were received through fabric, Internal, Sol-Air, etc. for both compounds (Figs.5.3.1 \& 5.3.2). As most of these heat gains come from fixed elements that not easy to retrofit in reality. Therefore, the study has focused on possible and feasible strategies that are doable and quick in installation such as replacing single pane windows with double pane windows and adding external shading devices. 


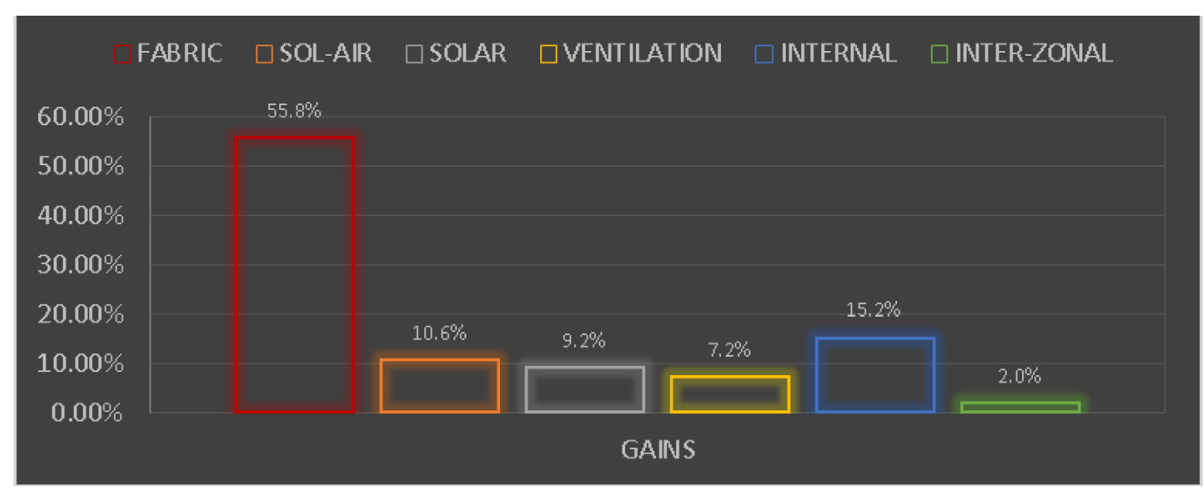

Fig. 5.3.1. Gains Breakdown for Baseline Case with Single Glazing Type in summer (Al Khwarizmi Compound).

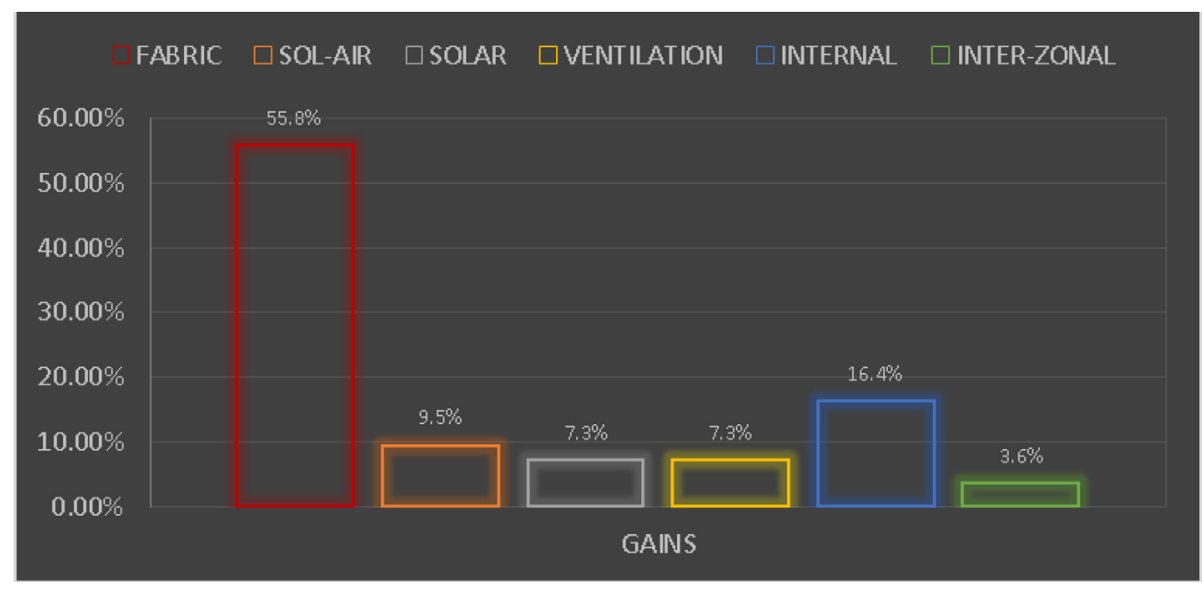

Fig. 5.3.2. Gains Breakdown for Baseline Case with Single Glazing Type in summer (Al Baironi Compound).

\section{- Cases from 1A-1C}

Double glazing panes have replaced single glazing panes in the simulation of Case1A in order to reduce heat transfer through convention, while in the Case of $1 \mathrm{~B}$ shading devices have been added to the windows to block sun radiation penetrating indoor spaces. One more case combing Case1A with Case1B was introduced in Case1C in order to reduce indoor temperature and accordingly decreasing cooling loads. According to the simulation shown in figure (5.3.3), the reduction is dropped from $9.20 \%$ to $4 \%$ with an improvement of 5.20\%. Similar investigation has been done for the case of Al Baironi and it is found in that Case2 has a smaller heat reduction than Case1 Figure (5.3.2 \& 5.3.4). Going through the simulation for all cases, the reduction was dropped from $7.5 \%$ to $5 \%$ with an improvement of $2.30 \%$ (Fig.5.3.4). 


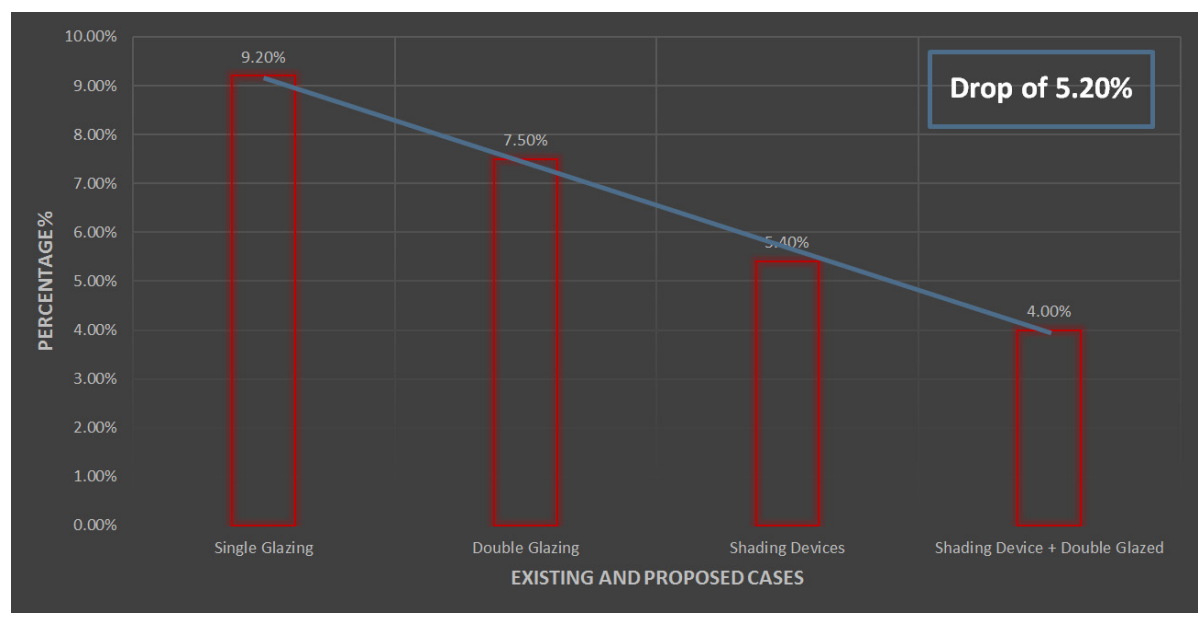

Fig. 5.3.3. Solar Heat Reduction in summer for the case of Khwarizmi Compound.

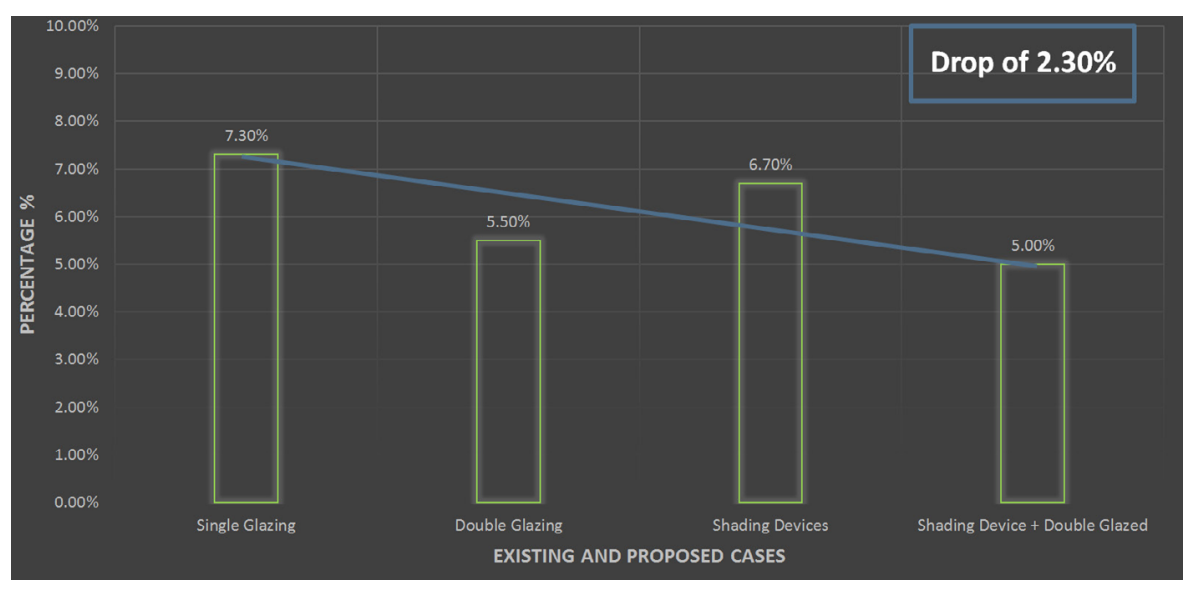

Fig. 5.3.4. Solar Heat Reduction in summer for the case of AL Baironi Compound.

\subsection{Solar gain reduction comparison}

Comparing the compounds of $\mathrm{Al}$ Khwarizmi and Al Baironi, The analysis in Figure.5.4.1 shows that the double glazing proposal is more effective for Al Baironi Compound than the shading devices proposal, while both proposals are effective in Al Khwarizmi Compound, because of its form (U-Formed) and compound's orientation. 


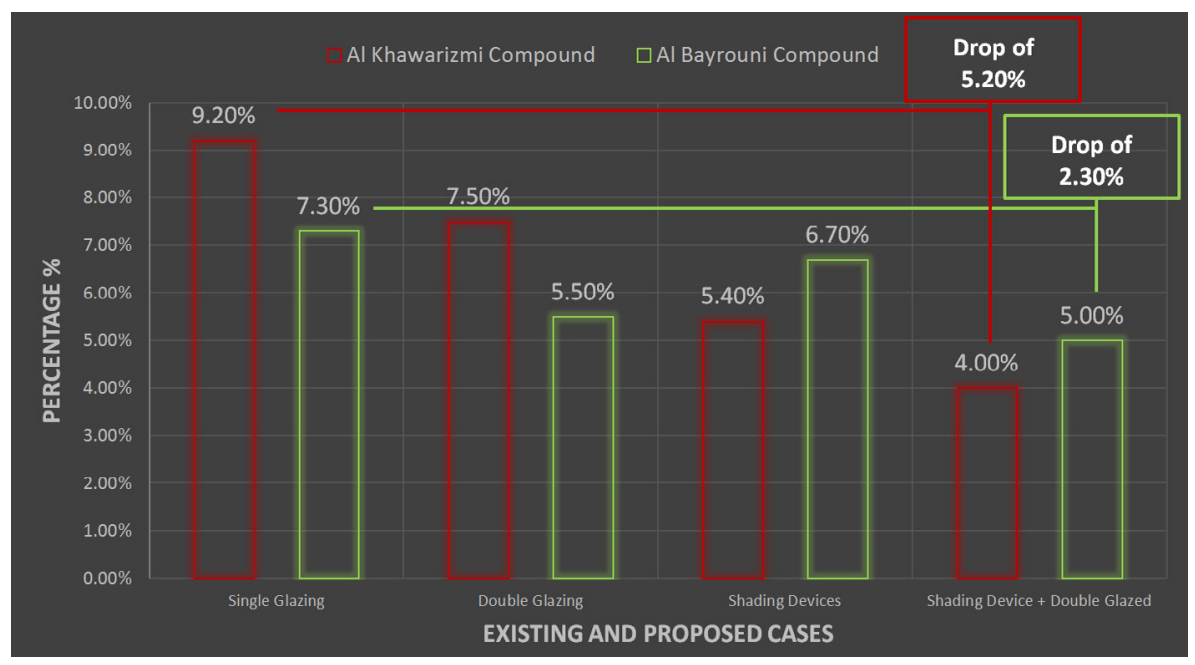

Fig. 5.4.1 Solar Heat Reduction in summer for both compounds.

\subsection{Monthly cooling loads for both compounds}

Analysis of the cooling loads of all cases, including the existing case for each compound were simulated separately, and then combined in one chart as in Fig.5.1.1 in order to compare the impact of each parameter on cooling loads for both compounds.

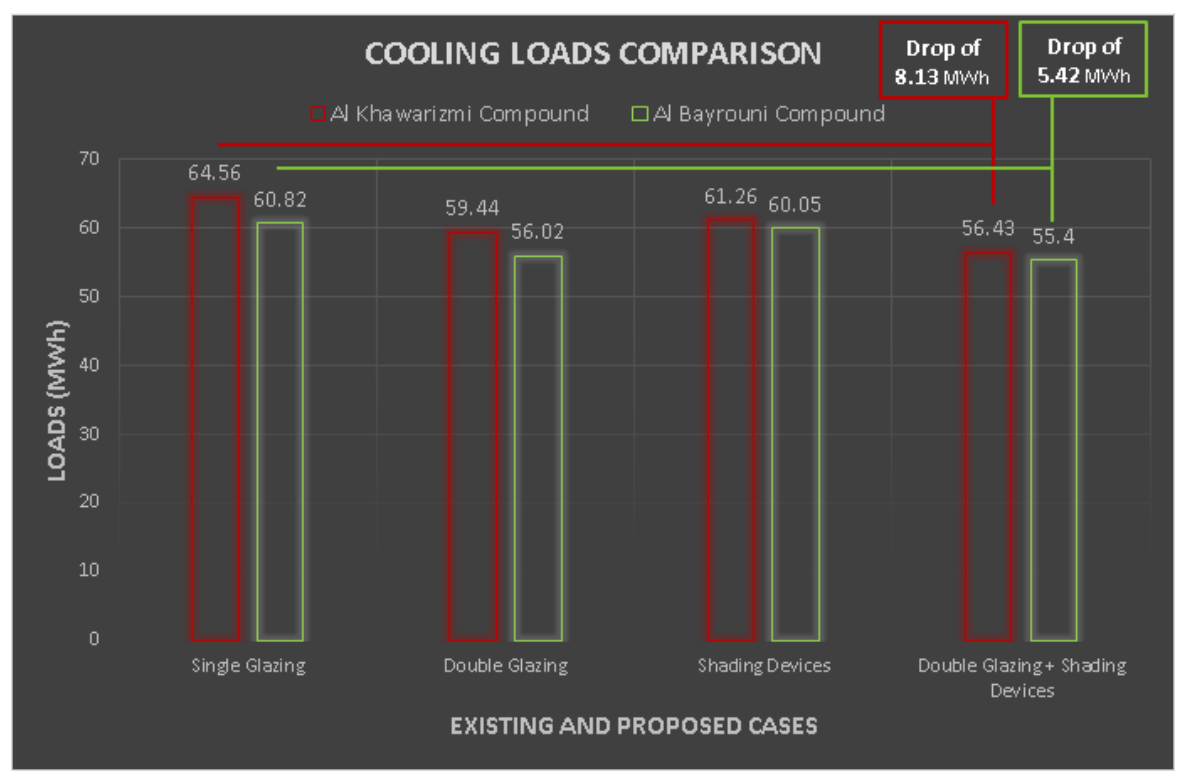

Fig. 5.1.1. Cooling Loads Reduction Comparison Chart.

From the analysis, it shows that the case of Al Khwarizmi consumed more cooling load than the case of $\mathrm{Al}$ Baironi with a difference of $3.73 \mathrm{MWh}$ to reach to $64.56 \mathrm{MWh}$. The total reduction in last case $1 \mathrm{C}$ reached to $55.64 \mathrm{MWh}$ from $60.84 \mathrm{MWh}$ with an improvement of 8.13 MWh. The other compound the Al Baironi has dropped from 60.82 $\mathrm{MWh}$ to 55.4 MWh with an improvement of 5.42 MWh. 


\section{Conclusion}

To build a comfortable indoor environment, many decisions should have been taken into consideration when designing residential compounds. Building forms and shapes besides the orientation of buildings and the materials used in construction are very important aspects to consider. In the university city of Sharjah single glazed windows are used where windows play an important role in reducing solar radiation. It is necessary to introduce more effective windows materials with better insulation values. From the study, after changing the material of windows from single to double glazing panes, the results were showed an improvement in the thermal performance of the building and helped in energy saving. Another strategy applied was adding shading device to the building facades helped in improving the indoor environment. Therefore, combining several passive design tools together to get the maximum benefit would definitely positively impact buildings. Thus, a number of other points that have not been covered in this should be explored in future studies. Further techniques and applications have to be investigated and integrated to the study in order to help the university reduce energy consumption in all residential and educational buildings.

\section{References}

1. Anthony, C. M. Indoor Climate of Multi-storey Hospital Buildings in Hot Humid Regions. An attemt to achieve comfortable indoor climate through passive climatic design in Ampara, Sri Lanka, p. 21.

2. Climate, Sharjah Climate History. (n.d.). Retrieved from My Weather: http://www.myweather2.com/City-Town/United-Arab-Emirates/Sharjah/climateprofile.aspx?month $=1$

3. ECOTECT TUTORIAL: Calculate Passive Gains Breakdown. (n.d.). Retrieved from wiki.natural frequency: http://wiki.naturalfrequency.com/wiki/Passive_Gains_Breakdown

4. Lin, J. (2007, Nov. 18). Introduction to ECOTECT V5.6. Retrieved from Tools for Sustainablity: http://www.toolsforsustainability.com/files/downlo (lin, introduction to ecotect v5.6, nov.18, 2007)ad/tutorials/ecotect/ecotecttutorial-thermalanalysis.pdf

5. Chapter 2 A Brief History of Thermal Comfort: From Effective Temperature to Adaptive Thermal Comfort 